\title{
Prevalence of Bacteriological Isolates Recovered from Faecal Sample of Domestic Cats
}

\author{
Bansari S. Patel ${ }^{1 *}$, Sunant K. Raval ${ }^{1}$, Bharat B. Bhanderi ${ }^{2}$ and Bhargav B. Limbachiya ${ }^{2}$ \\ ${ }^{1}$ Department of Veterinary Medicine, ${ }^{2}$ Department of Veterinary Microbiology, College of \\ Veterinary Science and Animal Husbandry, Anand Agricultural University, \\ Anand, Gujarat, India \\ *Corresponding author
}

\begin{abstract}
A B S T R A C T
\section{Keywords}

Bacteriological isolates, Faecal sample, Domestic cats

Article Info

Accepted:

22 July 2018

Available Online:

10 August 2018

The study was performed for prevalence of bacteriological isolates recovered from faecal samples of domestic cats and their antibiotic sensitivity pattern. Total thirty rectal swabs were collected from Baroda for bacteriological isolation. The overall prevalence of bacteria was $93.33 \%$ (28). The prevalence of E. coli, Streptococcus spp., Staphylococcus spp., gram positive bacilli, gram negative coccobacilli and gram positive coccobacilli were $36.67 \%$ (11), $23.33 \%$ (7), $10.00 \%$ (3), $10.00 \%$ (3), $10.00 \%$ (3) and $03.33 \%$ (1) respectively. In-vitro antibiotic sensitivity pattern of all the bacterial isolates recovered from faecal samples of domestic cats revealed that the isolates were more sensitive to Gentamicin (71.43\%) followed by Co-trimoxazole (57.14\%), Colistin (33.33\%), Enrofloxacin and Amoxyclav (28.57\% each), Tetracycline (19.05\%) and Ampicillin $(14.29 \%)$.
\end{abstract}

\section{Introduction}

The cat (Felis catus) is also known as domestic cat or house cat to distinguish it from the felines and felids.

It is a small furry domesticated carnivorous mammal that is valued by humans for its companionship household pets. Cats have been associated with humans for at least 9,500 years, and are currently the most popular pet in the world (Driscoll et al., 2009). Owing to their close association with humans, cats are now found almost everywhere in the world. Cats are the most favorite pets after dogs.
The intestinal microbiota is the collection of the living microorganisms (bacteria, fungi, protozoa, and viruses) inhabiting the gastrointestinal (GI) tract. Novel bacterial identification approaches have revealed that the gastrointestinal microbiota of dogs and cats is, similarly to humans, a highly complex ecosystem, comprising at least several hundred different bacterial phylotypes (Suchodolski et al., 2009). It has been suggested that the intestine of mammals is home to a total of 1010-1014 microbial cells, which is approximately 10 times more than the number of host cells. This complex microbial ecosystem and its interplay with 
eukaryotic host cells have a significant impact on health and disease of cats.

Based on traditional bacterial culture, the small intestine of dogs and cats harbors generally low bacterial counts, ranging between 102 to $105 \mathrm{cfu} / \mathrm{g}$ of small intestinal content; Cats appear to have higher counts of anaerobic bacteria compared to dogs in the proximal small intestine (Johnston et al., 1993). The total bacterial count in the colon ranges between approximately 109 and 1011 cfu/g and the most abundant cultivable groups are Bacteroides, Clostridium, Lactobacillus, Bifidobacterium, and Enterobacteriaceae (Mentula et al., 2005).

On average, 10 different bacterial phyla have been identified in the feline gut, with Firmicutes, Bacteroidetes, Proteobacteria, Fusobacteria, and Actinobacteria making up the vast majority of all gut microbes (Desai et al., 2009). Minor abundant members are the phyla Tenericutes, Verrucomicrobia, Cyanobacteria, and Chloroflexi. The Firmicutes contain various sequences affiliated with Clostridium cluster IV and Clostridium cluster XIVa and these are together with Bacteroides or Prevotella the predominant bacterial groups in fecal samples (Handl et al., 2011). Helicobacter are the predominant group in the stomach (> 90\% of sequencing reads) (Wagner, 2008), while the duodenum is home to Enterobacteriaceae, Clostridiales, Bacteroidales, and Lactobacillales.

The gastrointestinal microbiota has a strong impact on the health of cats and the microbiome can be altered in GI disease (Bell et al., 2008). The intestinal microbiota plays a crucial role in the development of the host immune system, protection against pathogens, toxins and mutagens and utilization of excess nutrients or nutrients that are unavailable to the host (Inness et al., 2007). Alterations of the normal gut microbiota balance due to inherent, environmental or immunological factors can be involved in the pathogenesis of intestinal inflammatory diseases.

\section{Materials and Methods}

\section{Collection}

During survey work total 30 rectal swabs were aseptically collected from domestic cats with help of sterile swab.

\section{Isolation}

The rectal swab was inoculated on MacConkey agar and blood agar for primary isolation of bacteria and later on sub culture on MacConkey agar and Eosine Methylene Blue (EMB) agar for isolation and identification.

The inoculated plates were examined for morphological, characteristics and growth of bacterial colonies after $24-48 \mathrm{~h}$ incubation period. The isolates were then identified on the basis of colony characteristics, staining characteristics (after staining with Gram's stain) microscopic morphology, lactose fermenting ability on MacConkey agar and greenish metallic sheen on EMB agar.

The Gram-positive cocci in chains were identified as Streptococcus spp. and in cluster were identified as Staphylococcus spp. on the basis of morphological characteristics. The gram negative coccobacilli isolates recovered on MacConkey agar with lactose fermenting pink colour colony on the culture plates. The greenish metallic sheen colonies were identified as E. colion EMB agar plates.

\section{Antibiotic sensitivity test}

All the isolates confirmed by primary test were subjected for antimicrobial sensitivity 
test. The antimicrobial sensitivity test was carried out by disc diffusion technique of Bauer et al., (1966) using seven antimicrobials. Mueller-Hinton agar plates were prepared, and the samples were inoculated. Antibiotic discs were placed at specific distance, and the plates were incubated at $37^{\circ} \mathrm{C}$ for $24 \mathrm{~h}$. The results were read by measuring the zone of inhibition produced by various antibiotic discs and compared to the standards. The antibiotic discs used were ampicillin (AMP; $10 \mathrm{mcg}$ ), gentamicin (GEN; $10 \mathrm{mcg}$ ), enrofloxacin (EX; $10 \mathrm{mcg}$ ), co-trimoxazole (COT; $25 \mathrm{mcg}$ ), colistin (methane sulphonate) (CL; $10 \mathrm{mcg}$ ), amoxyclav (amoxycillin-clavulanic acid) (AMC; $30 \mathrm{mcg})$, and tetracycline $(30 \mathrm{mcg}$ ).

\section{Results and Discussion}

\section{Bacteriological isolates recovered from faecal samples of domestic cats}

In the present investigation, bacteriological culture examination of rectal swabs from 30 cats, resulted the recovery of a total 28 bacterial isolates either in pure culture and/or as part of mixed infection. The bacteriological prevalence from faecal samples of domestic cats is presented in Table 1. The overall prevalence of bacteria was $93.33 \%$ (28/30). Of these, monomicrobic isolates were recovered from $76.67 \%$ (23/30) cats whereas more than one bacteria were found in case of $16.67 \%$ (5/30) cats. E. coli was found as a major isolate from faeces of cats. Total 11 cats were infected with $E$. coli infection. Out of total $(n=11)$ positive samples $(n=5)$ samples were mixed with Streptococcus spp. The prevalence of E. coli was $36.67 \%$ (11/30). Streptococcus spp. was recovered from $(n=7)$ samples of domestic cats, out of them $(n=5)$ samples were recovered as mixed isolates along with $E$. coli. The prevalence of Streptococcus spp. was $23.33 \%$ (7/30).Out of 30 samples Staphylococcus spp. was recovered from $(\mathrm{n}=3)$ faecal samples with the prevalence of $10.00 \%$ in domestic cats. Gram positive bacilli was also recovered from $(n=3)$ feacal samples with the prevalence of $10.00 \%$.Gram negative coccobacilli was isolated from $(n=3)$ faecal samples with the prevalence of $10.00 \%$.Gram positive coccobacilli was also recovered from $(\mathrm{n}=1)$ faecal sample and the prevalence was $03.33 \%$ in domestic cats.

\section{In-vitro antibiotic sensitivity test}

Total 28 bacterial isolates recovered from faecal samples of domestic cats. Out of 28 isolates, 21 isolates were subjected for in-vitro antibiotic sensitivity test. In-vitro antibiotic sensitivity pattern of all the 21 bacterial isolates recovered from faecal samples of domestic cats were shown in Table 2 and Figure 1. In-vitro antibiotic sensitivity pattern of all the bacterial isolates recovered from faecal samples of domestic cats revealed that the isolates were more sensitive to gentamicin $(71.43 \%)$ followed by co-trimoxazole $(57.14 \%)$, colistin $(33.33 \%)$, enrofloxacin and amoxyclav (28.57\% each), tetracycline (19.05\%) and ampicillin (14.29\%).E. coli isolates were highly sensitive to colistin (100\%) followed by gentamicin $(66.67 \%)$, cotrimoxazole $(50.00 \%)$ and the least to amoxyclav (16.67\%). ampicillin, enrofloxacin and tetracycline drugs were reported as highly resistant drugs $(100 \%)$ against $E$. coli isolates. Streptococcus spp. was highly susceptible to enrofloxacin (100\%), followed by tetracycline $(60.00 \%)$, enrofloxacin, co-trimoxazole, and amoxyclav (40.00\% per cent each) and ampicillin (20.00\%). Colistin drug was reported as highly resistant drug (100\%) against Streptococcus spp. Staphylococcus spp. isolates were higher susceptible to gentamicin $(66.67 \%)$, followed by cotrimoxazole, enrofloxacin and amoxyclav drugs (33.33\% each). Colistin, ampicillin and tetracycline reported as highly resistant drugs (100\%) against Staphylococcus spp. isolates. 
Gram positive bacilli isolates were highly sensitive to gentamicin (100\%) followed by co-trimoxazole andamoxyclav (66.67\% each) and tetracycline (33.33\%). Ampicillin, enrofloxacin, and colistin drugs were reported as highly resistant drugs (100\%) against Gram positive bacilli isolates. Gram negative coccobacilli isolates werehighly susceptible to co-trimoxazole (100\%), followed by ampicillin and enrofloxacin (66.67\% each), gentamicin and colistin (33.33\% each). Amoxyclav and tetracycline were highly resistant drugs (100\%) against Gram negative coccobacilli. In present study Gram positive coccobacilli isolates were highly sensitive to gentamicin, enrofloxacin and co-trimoxazole (100\% each). Ampicillin, colistin, amoxyclav and tetracycline drugs were reported as highly resistant drugs $(100 \%)$ against Gram positive coccobacilli isolates.

Table.1 Bacteriological prevalence from faecal samples of domestic cats

\begin{tabular}{|l|c|c|}
\hline \multicolumn{2}{|c|}{ Name of Bacteria } & $\begin{array}{c}\text { Total no. of animals screened and } \\
\text { bacteriological prevalence rate }\end{array}$ \\
\hline A. & Streptococcus spp. & N=30 \\
\hline B. $\quad$ Staphylococcus spp. & $7(23.33 \%)$ \\
\hline C. & E.coli & $3(10.00 \%)$ \\
\hline D. & Gram positive bacilli & $11(36.67 \%)$ \\
\hline E. & Gram negative coccobacilli & $3(10.00 \%)$ \\
\hline F. & Gram positive coccobacilli & $3(10.00 \%)$ \\
\hline & $\quad$ Total & $1(3.33 \%)$ \\
\hline
\end{tabular}

Table.2 Summary of bacterial isolates recovered from faecal samples of domestic cats and their Antibiogram pattern

\begin{tabular}{|c|c|c|c|c|c|c|c|c|c|}
\hline \multirow{2}{*}{$\begin{array}{l}\text { Sr. } \\
\text { No. }\end{array}$} & \multirow[t]{2}{*}{ Organism } & \multirow{2}{*}{$\begin{array}{c}\text { No. of } \\
\text { Isolate } \\
\mathrm{s}\end{array}$} & \multicolumn{7}{|c|}{ SENSITIVITY (\%) } \\
\hline & & & AMP & GEN & EX & COT & CL & AMC & TE \\
\hline 1 & E. coli & 6 & $00.00 \%$ & $66.67 \%$ & $00.00 \%$ & $50.00 \%$ & $100 \%$ & $16.67 \%$ & $00.00 \%$ \\
\hline 2 & $\begin{array}{l}\text { Streptococcus } \\
\text { spp. }\end{array}$ & 5 & $20.00 \%$ & $100 \%$ & $40.00 \%$ & $40.00 \%$ & $00.00 \%$ & 40.00 & $60.00 \%$ \\
\hline 3 & $\begin{array}{c}\text { Staphylococcus } \\
\text { spp }\end{array}$ & 3 & $00.00 \%$ & $66.67 \%$ & $33.33 \%$ & $33.33 \%$ & $00.00 \%$ & $33.33 \%$ & $00.00 \%$ \\
\hline 4 & $\begin{array}{l}\text { Gram positive } \\
\text { bacilli }\end{array}$ & 3 & $00.00 \%$ & $100 \%$ & $00.00 \%$ & $66.67 \%$ & $00.00 \%$ & $66.67 \%$ & $33.33 \%$ \\
\hline 5 & $\begin{array}{c}\text { Gram negative } \\
\text { coccobacilli }\end{array}$ & 3 & $66.67 \%$ & $33.33 \%$ & $66.67 \%$ & $100 \%$ & $33.33 \%$ & $00.00 \%$ & $00.00 \%$ \\
\hline$\overline{6}$ & $\begin{array}{l}\text { Gram positive } \\
\text { coccobacilli }\end{array}$ & 1 & $00.00 \%$ & $100 \%$ & $100 \%$ & $100 \%$ & $00.00 \%$ & $00.00 \%$ & $00.00 \%$ \\
\hline
\end{tabular}


Fig.1 In vitro antibiotic pattern to all bacterial isolates recovered from faecal samples of domestic cats

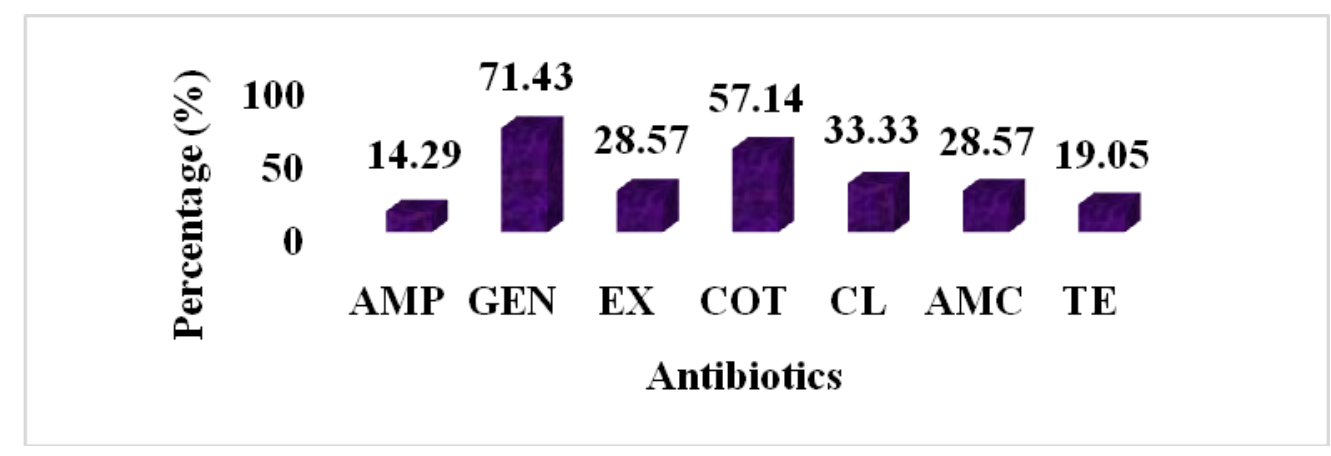

In present study the prevalence of $E$. coli was $36.67 \%$ (11). Apart from these communications, Costa et al., (2008) have also reported that two Escherichia coli isolates per sample were recovered (66 of cats). Gumus et al., (2017) isolated E. coli from rectal swabs of 192 healthy cats, and 82 E. coli were isolated $(\mathrm{n}=82)$. All samples were incubated for $18 \mathrm{~h}$ at $37^{\circ} \mathrm{C}$ in tryptic soy broth (TSB) and subcultured on MacConkey agar. In present study the prevalence of Streptococcus spp. was $23.33 \%$ (7). Lysková et al., (2007) also recovered Streptococcus spp. from 4 samples of 34 faecal samples. The prevalence of Staphylococcus spp. in this study was $10.00 \%$ (3). Bierowiec et al., (2016) reported the prevalence of Staphylococcus aureus from faecal samples of cats were $17.5 \%$ (7). In present study the prevalence of gram positive bacilli was $10.00 \%$ (3). Andrzejewska et al., (2013) isolated 7 Campylobacter spp. from 71 cats from Bydgoszcz region, and prevalence was 9.86\%. Polzler et al., (2018) also recovered Campylobacter from 344 cats in Styria, Austria and prevalence of Campylobacter spp. was 22 (6.4\%). The differences in the occurrence of bacteria might be due to the differences in epidemiological conditions between countries. The antibiotic susceptibility patterns of all isolates found in our study are generally in agreement with the findings of other authors Abdallah (2005) reported that E.coli isolates were $47 \%$ resistant to tobramycin, gentamycin, penicillin, tetramycin, cefoperazone, erythromycin, chloramphenicol, sulfa, trimethoprim, doxycycline, rifampicin, streptomycin, ofloxacin, cephradine, ceftriaxane, cefotaxime, clindamycin, ampicillin, amoxicillin, nitrofurantoin, norfloxacin, and carbenicillin. Murphy et al., (2009) reported the prevalence of antimicrobial resistance in $E$. coli was as follows: streptomycin (2\%), ampicillin (4\%), cephalothrin (1\%), and tetracycline (2\%). Kanagarajah et al., (2017) reported that feline MRSA isolates resistance were as follows, methicillin (100\%), ceftazidime (100\%), enrofloxacin $(92.31 \%)$, oxacillin $(84.62 \%)$ and vancomycin (0\%), $84.62 \%$ of feline MRSA isolates indicated resistance to four out of five antibiotics tested. Lazou et al., (2017) reported that all Campylobacter isolates exhibited susceptibility to erythromycin, gentamicin and streptomycin. Contrariwise, $4.5 \%$ of feline isolates were resistant to quinolones, quinolones along with tetracycline and tetracycline alone, respectively. Rodrigues et al., (2015) reported that more than $50 \%$ of the Campylobacter spp. resistant to ceftiofur, sulphazotrim, norfloxacin and tetracycline. In this study, all bacterial isolates were more resistance to ampicillin and tetracycline. However, due to increasing resistance of bacterial isolates to 
antimicrobial agents, there is need to emphasize the importance of susceptibility testing in order to establish correct therapeutic protocol.

In conclusions ampicillin was found to be more resistant on faecal sample so in such cases avoid the use of ampicillin in intestinal infection. Gentamicin was sensitive on faecal sample culture followed by co-trimaxazole, colistin, enrofloxacin, amoxyclav and tetracycline.

\section{Acknowledgements}

This work was supported by faculty of Veterinary Medicine and Veterinary Microbiology, College of Veterinary Science and Animal Husbandry, Anand.

\section{References}

Abdallah, S. A. (2005). Detection and Differentiation of Escherichia coli Populations from Human, Animal and Avian Feces, and Different Water Sources. Polish Journal of Environmental Studies, 14(5).

Andrzejewska, M., Szczepańska, B., Klawe, J. J., Śpica, D., and Chudzińska, M. (2013). Prevalence of Campylobacter jejuni and Campylobacter coli species in cats and dogs from Bydgoszcz (Poland) region. Polish journal of veterinary sciences, 16(1), 115-120.

Bauer, A. W., Kirby, W. M. M., Sherris, J. C., and Turck, M. (1966). Antibiotic susceptibility testing by a standardized single disk method. American journal of clinical pathology. 45(4), 493.

Bell, J. A., Kopper, J. J., Turnbull, J. A., Barbu, N. I., Murphy, A. J., and Mansfield, L. S. (2008). Ecological characterization of the colonic microbiota of normal and diarrheic dogs. Interdisciplinary perspectives on infectious diseases.
Bierowiec, K., Płoneczka-Janeczko, K., and Rypuła, K. (2016). Prevalence and risk factors of colonization with Staphylococcus aureus in healthy pet cats kept in the city households. BioMed research international.

Costa, D., Poeta, P., Sáenz, Y., Coelho, A. C., Matos, M., Vinué, L., and Torres, C. (2008). Prevalence of antimicrobial resistance and resistance genes in faecal Escherichia coli isolates recovered from healthy pets. Veterinary microbiology, 127(1-2), 97-105.

Desai, A. R., Musil, K. M., Carr, A. P., and Hill, J. E. (2009). Characterization and quantification of feline fecal microbiota using cpn60 sequence-based methods and investigation of animal-to-animal variation in microbial population structure. Veterinary microbiology, 137(1-2), 120-128.

Gumus, B., Celik, B., Kahraman, B. B., Sigirci, B. D., and Ak, S. (2017). Determination of extended spectrum beta-lactamase (ESBL) and AmpC betalactamase producing Escherichia coli prevalence in faecal samples of healthy dogs and cats. Revue De Medecine Veterinaire, 168(1-3), 46-52.

Handl, S., Dowd, S. E., Garcia-Mazcorro, J. F., Steiner, J. M., and Suchodolski, J. S. (2011). Massive parallel 16S rRNA gene pyrosequencing reveals highly diverse fecal bacterial and fungal communities in healthy dogs and cats. FEMS microbiology ecology, 76(2), 301-310.

Inness, V. L., McCartney, A. L., Khoo, C., Gross, K. L., and Gibson, G. R. (2007). Molecular characterisation of the gut microflora of healthy and inflammatory bowel disease cats using fluorescence in situ hybridisation with special reference to Desulfovibrio spp. Journal of animal physiology and animal nutrition, 91(1- 2), 48-53. 
Johnston, K., Lamport, A., and Batt, R. M. (1993). An unexpected bacterial flora in the proximal small intestine of normal cats. The Veterinary Record, 132(14), 362-363.

Kanagarajah, R. R., Lee, D. C. W., Lee, D. Z. F., Yusoff, K., Paramasivam, S. J., Low, W. Y., and Lim, S. H. E. (2017). Antibiotic profiling of Methicillin Resistant Staphylococcus aureus (MRSA) isolates in stray canines and felines. Cogent Biology, 3(1), 141-228.

Lazou, T., Fragkou, F., Gelasakis, A., Dovas, C., Soultos, N., Adamama-Moraitou, K., and Iossifidou, E. (2017). Prevalence, antimicrobial resistance and risk factors for Campylobacter colonising dogs and cats in Greece. Bulgarian Journal of Veterinary Medicine, 20(3).

Lysková, P., Vydržalová, M., Královcová, D., and Mazurová, J. (2007). Prevalence and characteristics of Streptococcus canis strains isolated from dogs and cats. Acta Veterinaria Brno, 76(4), 619625.

Mentula, S., Harmoinen, J., Heikkilä, M., Westermarck, E., Rautio, M., Huovinen, P., and Könönen, E. (2005). Comparison between cultured smallintestinal and fecal microbiotas in beagle dogs. Applied and environmental microbiology, 71(8), 4169-4175.

Murphy, C., Reid-Smith, R. J., Prescott, J. F., Bonnett, B. N., Poppe, C., Boerlin, P., and McEwen, S. A. (2009). Occurrence of antimicrobial resistant bacteria in healthy dogs and cats presented to private veterinary hospitals in southern Ontario: a preliminary study. The Canadian Veterinary Journal, 50(10), 1047.

Pölzler, T., Stüger, H. P., and Lassnig, H. (2018). Prevalence of most common human pathogenic Campylobacter spp. in dogs and cats in Styria, Austria. Veterinary Medicine and Science.

Rodrigues, C. G., Melo, R. T., Fonseca, B. B., Martins, P. A., Ferreira, F. A., Araújo, M. B., and Rossi, D. A. (2015). Occurrence and characterization of Campylobacter spp. isolates in dogs, cats and children. Pesquisa Veterinária Brasileira, 35(4), 365-370.

Suchodolski, J. S., Dowd, S. E., Westermarck, E., Steiner, J. M., Wolcott, R. D., Spillmann, T., and Harmoinen, J. A. (2009). The effect of the macrolide antibiotic tylosin on microbial diversity in the canine small intestine as demonstrated by massive parallel $16 \mathrm{~S}$ rRNA gene sequencing. $B M C$ microbiology, 9(1), 210.

Wagner, R. D. (2008). Effects of microbiota on GI health: gnotobiotic research. In GI microbiota and regulation of the immune system. Springer, New York, 41-56.

\section{How to cite this article:}

Bansari S. Patel, Sunant K. Raval, Bharat B. Bhanderi and Bhargav B. Limbachiya. 2018. Prevalence of Bacteriological Isolates Recovered from Faecal Sample of Domestic Cats. Int.J.Curr.Microbiol.App.Sci. 7(08): 3943-3949. doi: https://doi.org/10.20546/ijcmas.2018.708.406 